\title{
A Smart Polymer Composite Based on a NiTi Ribbon and a Magnetic Hybrid Material for Actuators with Multiphysic Transduction
}

\author{
Beatriz López-Walle ${ }^{1, *}$, Enrique López-Cuellar ${ }^{1}$, Edgar Reyes-Melo ${ }^{1}$, Osvaldo Lomas-González ${ }^{1}$ \\ and Walman B. de Castro ${ }^{2}$
}

1 FIME, Universidad Autónoma de Nuevo León, Ciudad Universitaria, C.P. 66451, San Nicolás de los Garza, N.L., México; E-Mails: enlopez_73@yahoo.com (E.L.-C.); reyesmeloedgar@yahoo.fr (E.R.-M.); osvilomas@hotmail.com (O.L.-G.)

2 Universidade Federal de Campina Grande, Aprígio Veloso 882-Bodocongó, C.P. 10069, Campina Grande, Paraíba, Brazil; E-Mail: walman.castro@ufcg.edu.br

* Author to whom correspondence should be addressed; E-Mail: beatriz.lopezwl@uanl.edu.mx; Tel.: +52-81-1340-4000 (ext. 1520).

Academic Editors: Mathieu Grossard and Micky Rakotondrabe

Received: 31 August 2015 / Accepted: 30 November 2015 / Published: 3 December 2015

\begin{abstract}
A smart composite material constituted of a magnetic hybrid film and a NiTi shape memory alloy (SMA) ribbon was obtained and characterized. The magnetic hybrid film was joined to the NiTi ribbon in order to combine the properties of both materials. This new composite material combines magnetic properties of the hybrid film, $\left(\mathrm{Fe}_{2} \mathrm{O}_{3}-\mathrm{CMC}\right) /($ polyvinyl butyral), and the shape memory properties of the NiTi ribbon, which has a chemical composition of Ti-50.13 at. \% Ni. This smart composite material has a mass of $18.3 \%$ NiTi ribbon and $81.7 \%$ magnetic hybrid film. Results obtained by DSC show that the smart composite material presents a small delay of transformation during warming and cooling because the magnetic hybrid film acts like a thermal insulator. Thermomechanical results indicate that the hybrid material also acts as a mechanical reinforcement, since it is observed that the Stress-Assisted Two-Way Memory Effect (SATWME) of the smart composite is lower than the SATWME of the SMA ribbon. The density current values of phase transformations were clearly identified with a thermomechanical apparatus developed in our laboratory. Finally, displacements of the smart composite material in cantilever configuration are obtained by applying an external magnetic field. All these results demonstrate that the smart composite material can be
\end{abstract}


activated by temperature, electrical current, stress, and/or magnetic field, offering good expectations for actuating applications with multiphysic transduction.

Keywords: composite materials; magnetic actuation; SMA; hybrid materials

\section{Introduction}

Composite materials should acquire properties of those materials forming the new material. They can even have different properties than the original ones. These kinds of materials are sometimes multifunctional or smart materials, and they can modify their mechanical or physical properties when a stimulus (thermal, electric, magnetic, etc.) is applied, and return to their original properties when the stimulus withdraws. Composites based on shape memory alloys (SMAs) are regarded as promising candidates for the so-called "smart composite materials" [1]. In this sense, shape memory composites, with either embedded or bonded shape memory material systems, provide tremendous potential for creating new paradigms in material-structural interactions [2-5]. The demand of shape memory composites for engineering and technical applications has been increasing in numerous commercial and industrial fields [2,3,6,7]. The possible applications include microgrippers, force sensors, microrelays, microvalves, micropumps, etc. [8-12]. The objective of this article is to present the first results of a smart composite material with multiphysic transduction that can be activated by several stimuli such as electrical current, temperature, stress, and magnetic field. In this novel material, the NiTi shape memory effect is combined with the viscoelastic, electrical and magnetic properties of a magnetic hybrid polymer consisting of iron oxide $\left(\mathrm{Fe}_{2} \mathrm{O}_{3}\right)$ nanoparticles coated with carboxymethyl cellulose (CMC), and embedded in a polymeric matrix of polyvinyl butyral (PVB). The SMA, with a chemical composition of Ti-50.13 at. $\% \mathrm{Ni}$, is a ribbon-shaped material fabricated by the melt-spinning technique. The magnetic behavior of the $\left(\mathrm{Fe}_{2} \mathrm{O}_{3}-\mathrm{CMC}\right) / \mathrm{PVB}$ hybrid material was described by López-Walle et al. [13]. Dynamic mechanical analysis (DMA) and thermomechanical tests for a similar composition of the SMA ribbon were discussed by Lomas-González et al. [14]. Here, the manufacturing and synthesis processes of each one of the constitutive materials and the composite material are first described. Then, the morphological characterization by SEM and the composition analysis of the smart composite material are shown. Differential scanning calorimetry (DSC) results for the NiTi ribbon, the hybrid material and the composite material are analyzed and compared. Finally, the multiphysic transduction by thermomechanical tests and magnetic experimentations is presented. Results validate multiphysic transduction for future interesting actuating applications.

\section{Manufacturing and Synthesis Processes}

As mentioned, the smart composite material is based on a NiTi SMA ribbon enclosed by a $\left(\mathrm{Fe}_{2} \mathrm{O}_{3}-\mathrm{CMC}\right) / \mathrm{PVB}$ magnetic hybrid film. This section describes the manufacturing process of each one of these materials. 


\subsection{NiTi SMA Ribbons}

The SMA ribbons were prepared at the Universidade Federal de Campina Grande, Brazil, by the single-roller melt-spinning technique. First, NiTi ingots were fabricated via a vacuum induction melting (VIM) process using a chemical composition of Ti-50.13 at. \% Ni. Then, the alloy ingots were loaded in a quartz crucible with a nozzle diameter of $1.0 \mathrm{~mm}$ under a 200 mbar argon atmosphere. Finally, the molten alloy was ejected onto the surface of a polished copper wheel with a tangential velocity fixed at $30 \mathrm{~m} / \mathrm{s}$. The dimensions of the continuous obtained ribbons are $30 \pm 5 \mu \mathrm{m}$ in thickness and $1.7 \pm 0.3 \mathrm{~mm}$ in width. Figure $1 \mathrm{a}$ shows a schema of the melt-spinning process and Figure $1 \mathrm{~b}$ shows a sample of the NiTi ribbon. More information about the preparation of the SMA ribbons is described by Nuñez-Mendoza et al. [15].
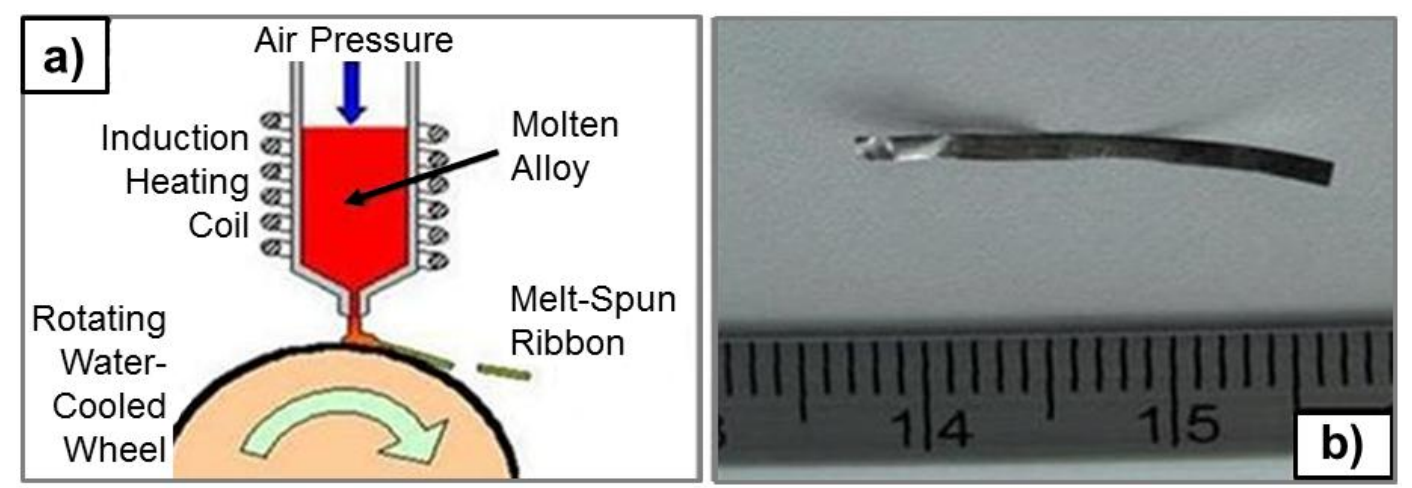

Figure 1. Melt-spinning process. (a) Schema. (b) Resulting NiTi ribbon (measures in mm).

\subsection{Magnetic Hybrid Material}

The magnetic hybrid material was prepared at Centro de Investigación, Innovación y Desarrollo en Ingeniería y Tecnología of the Facultad de Ingeniería Mecánica y Eléctrica (CIIDIT-FIME), at the Universidad Autónoma de Nuevo León (UANL). It consists of iron oxide $\left(\mathrm{Fe}_{2} \mathrm{O}_{3}\right)$ nanoparticles $(\sim 4 \mathrm{~nm})$ coated with carboxymethyl cellulose (CMC), embedded in polyvinyl butyral (PVB). López-Walle et al. reported all the details about the synthesis process [16,17]. Figure 2 depicted this process. In summary, a film of $\mathrm{Fe}_{2} \mathrm{O}_{3}-\mathrm{CMC}$ is synthetized, pulverized and dispersed in a polymer matrix of $\mathrm{PVB}$, finally obtaining the $\left(\mathrm{Fe}_{2} \mathrm{O}_{3}-\mathrm{CMC}\right) / \mathrm{PVB}$ magnetic film.

\subsection{Smart Composite Material}

In order to combine the magnetic and dielectric properties of the polymer film with the shape memory properties of the ribbons, the first one is joined to the second one by compressing them over $30 \mathrm{~min}$ at $348 \mathrm{~K}$, as illustrated in Figure 3a. A sample of the obtained composite material, called M1, is shown in Figure $3 b$.

The next section deals with the characterization of this smart composite material. 


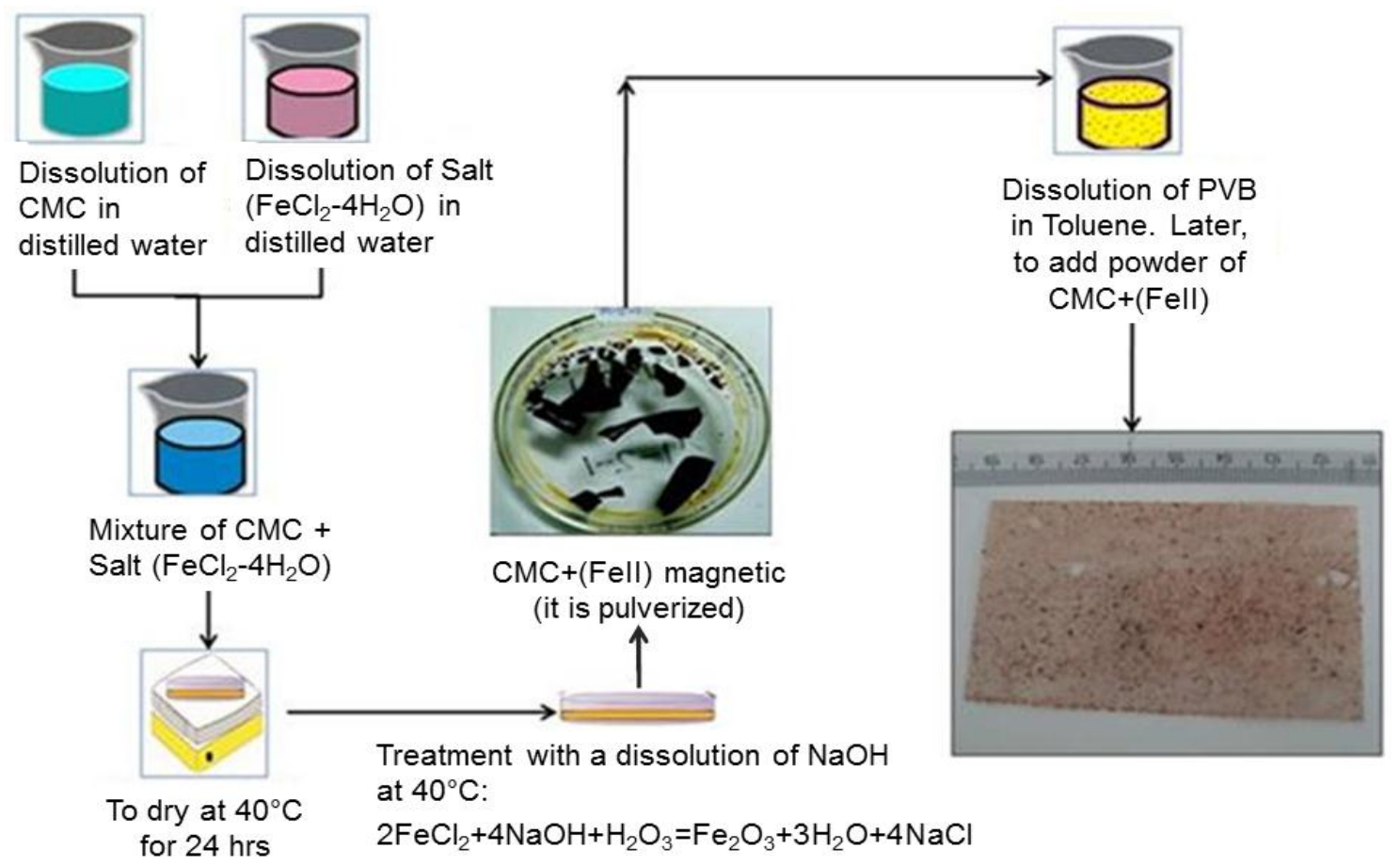

Figure 2. Process to obtain the $\left(\mathrm{Fe}_{2} \mathrm{O}_{3}-\mathrm{CMC}\right) / \mathrm{PVB}$ magnetic hybrid polymer.

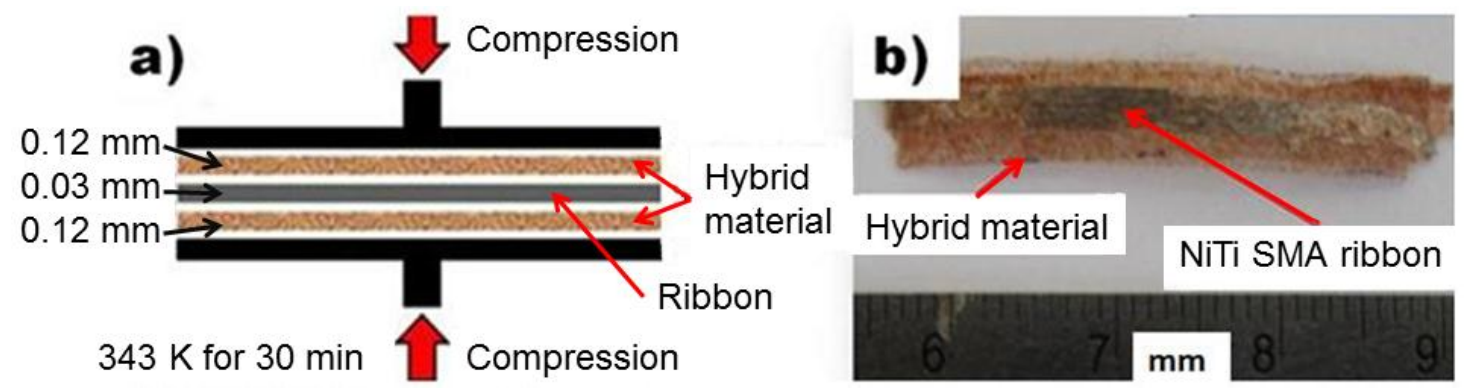

Figure 3. (a) Schema of the joining process of the magnetic hybrid film and the SMA ribbon (lateral view). (b) Smart composite material.

\section{Characterization}

Several characterization techniques have been employed to identify the morphology, composition and transformation temperatures of the composite material.

The morphology of the composite material was observed in a NOVA NANO SEM 200 (FEI) ion scanning electron microscope (SEM).

Then, the mass fractions of its composing materials (percentage of NiTi ribbon mass and percentage of magnetic hybrid film mass) are calculated.

The transformation temperatures of the NiTi ribbons, the magnetic hybrid film and the composite material are determined by differential scanning calorimetry (DSC), using a Diamond DSC from Perkin Elmer. These tests are carried out at $5 \mathrm{~K} / \mathrm{min}$ cooling and heating rates and the temperature scanning range was from $273 \mathrm{~K}$ to $393 \mathrm{~K}$. The masses of the samples are approximately between 5 and $8 \mathrm{mg}$. Results and discussion of these characterizations are presented in next paragraphs. 


\subsection{Morphology and Composition Analysis of the Smart Composite Material}

The smart composite material has been observed transversely by SEM in order to verify the adhesion between the magnetic hybrid material and the NiTi ribbon. In the section in Figure 4, red arrows show the zones where the magnetic hybrid film is not fully adhered to the SMA ribbon. Nevertheless, as described in the next sections, the adhesion between both materials is sufficient to consider that the obtained material is a composite material whose behavior is the result of the contribution of both materials: the magnetic hybrid material and the SMA ribbon.

Additionally, the mass fractions of both materials were empirically calculated. The length of the obtained material is about $3.5 \mathrm{~cm}$ and the masses of the NiTi ribbon and the magnetic hybrid film are $8.5 \mathrm{mg}$ and $46.5 \mathrm{mg}$, respectively. Thus, the NiTi ribbon represents $18.3 \%$ of the mass of the composite material, and the magnetic hybrid film corresponds to $81.7 \%$.

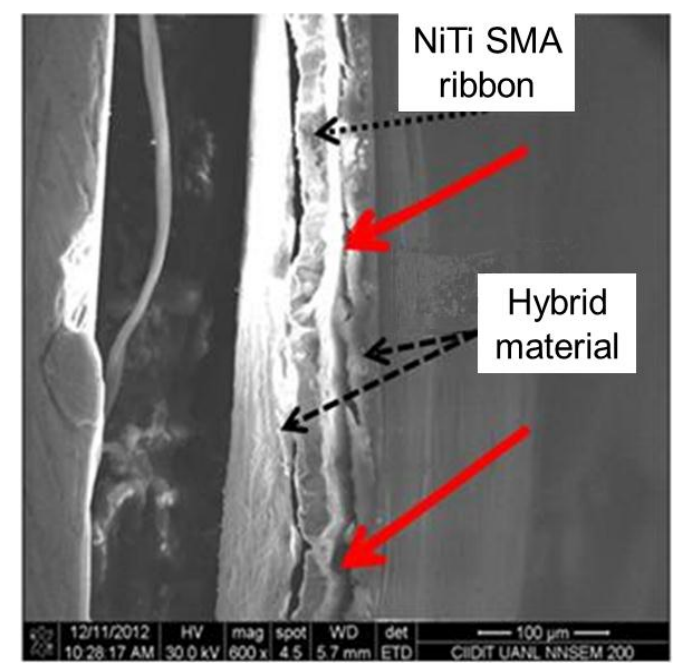

Figure 4. Transversal SEM view of the composite material at the union between the magnetic hybrid material and the NiTi ribbon. Red arrows show where adhesion is not fully completed.

\subsection{DSC Study of SMA Ribbons, Magnetic Hybrid Material and Smart Composite Material}

In this section, the phases and transformation temperatures obtained by DSC are described. For this, the NiTi ribbon (sample M1), the magnetic hybrid film and the developed composite material were tested. Figure 5 shows a comparison of their three respective DSC curves. As observed in these curves, the interesting temperatures, described in the next paragraphs, occur in a similar range of values.

The DSC lets us know the thermal transitions of the magnetic hybrid material, such as its glass transition temperature (Tg). The Tg for the PVB is $342 \mathrm{~K}$, approximately [18]. Furthermore, it has been found that the magnetic nanoparticles cause a significant decrease in Tg until about $327 \mathrm{~K}$. This phenomenon has been reported by Kirchberg et al. [18] and is validated here.

The DSC curve of the SMA ribbon M1 is also presented. It shows that the reversible martensitic transformation is observed for the NiTi ribbon fabricated by melt-spinning. This reversible transformation produces the shape memory effect. During cooling, a small imperfection is observed on the peak (see the red circle on Figure 5). We assume that this imperfection is caused by the presence of 
the R-phase [15]. Thus, the transformation seems to occur in three steps, from austenite to R-phase and finally to martensite. R-phase is relatively common in this kind of alloy [19,20]. The transformation temperatures obtained from this DSC curve are displayed in Table 1.

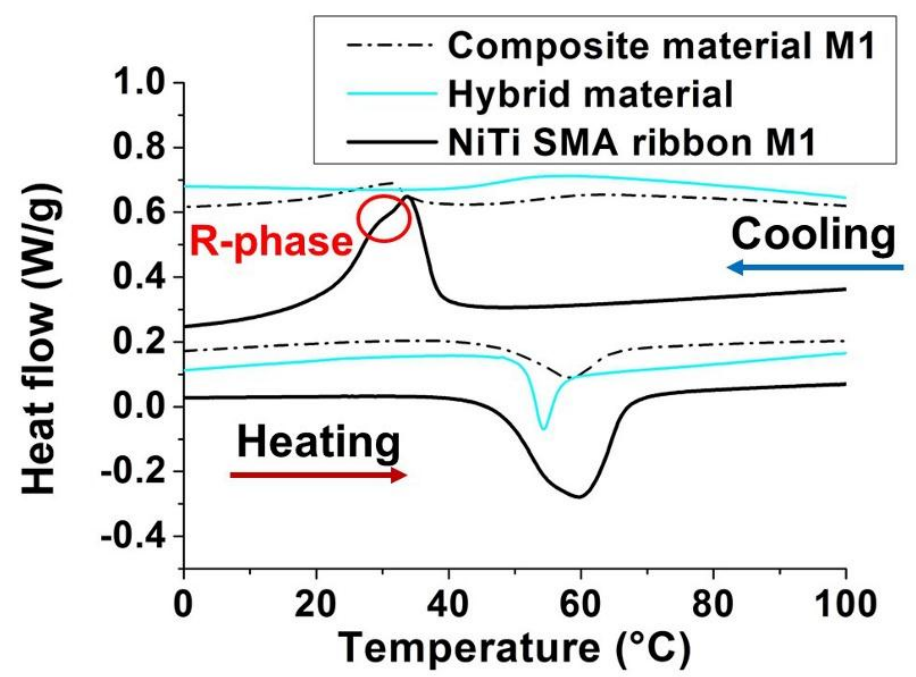

Figure 5. Comparison of DSC curves between the magnetic hybrid material, the NiTi ribbon and the composite material M1.

Table 1. Transformation temperatures of the SMA ribbon M1, obtained by DSC.

\begin{tabular}{cccccc}
\hline Sample & As $(\mathbf{K})$ & Af $(\mathbf{K})$ & Rs $(\mathbf{K})$ & $\mathbf{R f}+\mathbf{M s}(\mathbf{K})$ & Mf $(\mathbf{K})$ \\
\hline NiTi SMA ribbon M1 & 319.9 & 340.1 & 311.9 & 301.4 & 294.7 \\
\hline
\end{tabular}

Note: As: austenite transformation start; Af: austenite transformation finish; Rs: R-phase transformation start; Rf + Ms: R-phase transformation finish and martensitic transformation start; Mf: martensitic transformation finish.

Finally, the composite material was analyzed in order to compare its response to those of its constituent materials. As previously mentioned, the mass of the magnetic hybrid material is predominant. The behavior of the composite material is then affected by the insulating properties of the polymer. On the one hand, the intensity of the peaks is clearly reduced. On the other hand, the transformation temperatures are also affected. The temperature of the beginning of the austenitic transformation increases about $5 \mathrm{~K}(325.4 \mathrm{~K}$ for the composite material and $319.9 \mathrm{~K}$ for the NiTi ribbon) and the beginning of the martensitic transformation increases its temperature by $2 \mathrm{~K}(309.2 \mathrm{~K}$ for the composite material and $311.9 \mathrm{~K}$ for the NiTi ribbon). Table 2 shows the transformation temperatures for the composite material.

Table 2. Transformation temperatures of the composite material obtained by DSC.

\begin{tabular}{ccccc}
\hline Sample & As $(\mathbf{K})$ & Af $(\mathbf{K})$ & Ms $(\mathbf{K})$ & Mf $(\mathbf{K})$ \\
\hline Composite material M1 & 325.4 & 337.9 & 309.2 & 292.2 \\
\hline
\end{tabular}

In summary, the shape memory transformations and polymer transformation are still present in the DSC curve corresponding to the composite material. So, at this point, it is expected that the composite material could be activated by mechanical, thermal (by temperature or electrical current via Joule effect) and magnetic excitations. 


\section{Multiphysic Transduction}

The composite material can be activated by electrical current, temperature, stress or magnetic field. In this section we observe, and sometimes compare, the thermomechanical and magnetic behaviors of the composite material when it is stimulated by electrical current, considering different amounts of stress and magnetic fields. This study is necessary for future applications of this composite material.

\subsection{Thermomechanical Behavior by Electrical Stimulus of SMA Ribbons and Composite}

In order to compare the thermomechanical behavior of the NiTi ribbons and the composite material, we use an automated system developed in our laboratory [17]. In this equipment, the sample is heated by Joule effect and cooled in air by natural convection. Every cycle is performed under different amounts of constant stress in order to obtain complete cycles of the Stress-Assisted Two-Way Memory Effect (SATWME). During heating, a change of phase from martensite (B19') to austenite (B2) is produced, promoting a dimension change (principally in length) in the SMA. This change is measured with a linear variable differential transformer (LVDT) sensor. The reverse transformation occurs throughout cooling. The initial dimensions of the SMA ribbon are $1.2 \times 12 \times 0.03 \mathrm{~mm}^{3}$. An example of a curve of strain $(\% \varepsilon) v s$. current density $\left(\mathrm{A} / \mathrm{mm}^{2}\right)$ of a complete cycle of a SATWME cycle obtained with this equipment is presented and explained in Figure 6.

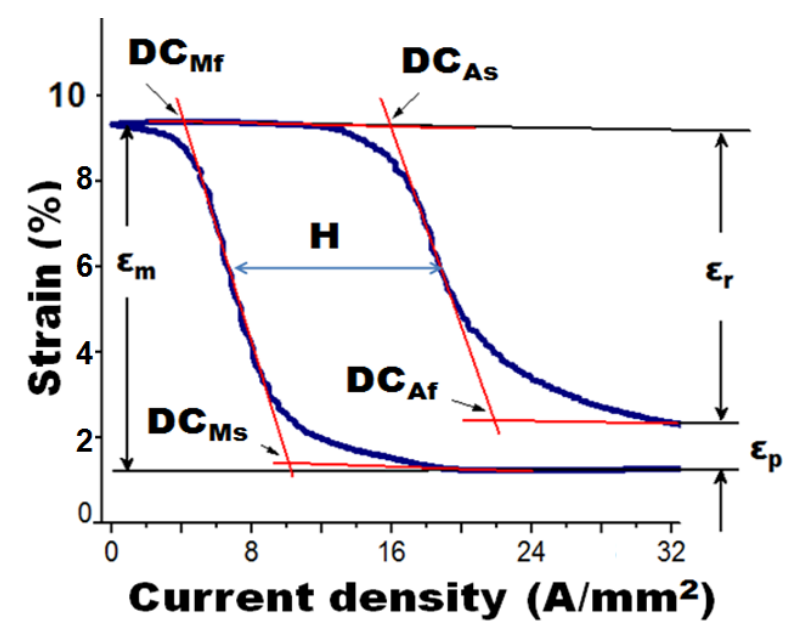

Figure 6. Martensitic transformation. $\varepsilon_{\mathrm{r}}$ : SATWME or strain recovery; $\varepsilon_{\mathrm{p}}$ : plastic deformation strain; $\mathrm{DC}_{\mathrm{Ms}}$ : start martensite transformation as a function of current density; $\mathrm{DC}_{\mathrm{Mf}}$ : finish martensite transformation as a function of current density; DC $\mathrm{As}_{\mathrm{As}}$ start austenite transformation as a function of current density; DCAf: finish austenite transformation as a function of current density; H: hysteresis.

In order to assure electrical continuity in the circuit, both extremities of the composite were grabbed directly from the NiTi ribbon with the metallic clamps of the thermomechanical machine. This allows us, on the one hand, to heat and achieve the phase transformations of the SMA ribbon without damaging the hybrid material and, on the other hand, to compare the mechanical response of the ribbon with and without hybrid material, both at the same level of applied stress. Figure 7 shows the SATWME plots of the NiTi ribbon and the composite sample for two stresses, $0 \mathrm{MPa}$ and $85 \mathrm{MPa}$. 
The current density values for phase transformations were obtained from these curves using the tangent method [21-24]; results are displayed in Table 3. From these results, the effect of the stress on current transformations can be deduced: the greater the applied stress, the greater the current density and, consequently, the transformation temperatures. In fact, transformation temperatures are analogous to current densities.

Additionally, the start phase transformations are retarded in the composite material due to the thermal and electrical insulating properties of the polymers. So, comparing both samples, the NiTi ribbon needs smaller amounts of current density to start the austenitic transformation during heating and, during cooling, to begin the martensitic transformation.

Concerning strain, the effect on it caused by the stress when the current density increases is reduced in the composite material compared to the NiTi ribbon. That is because the polymers in the composite materials act as a mechanical baking.
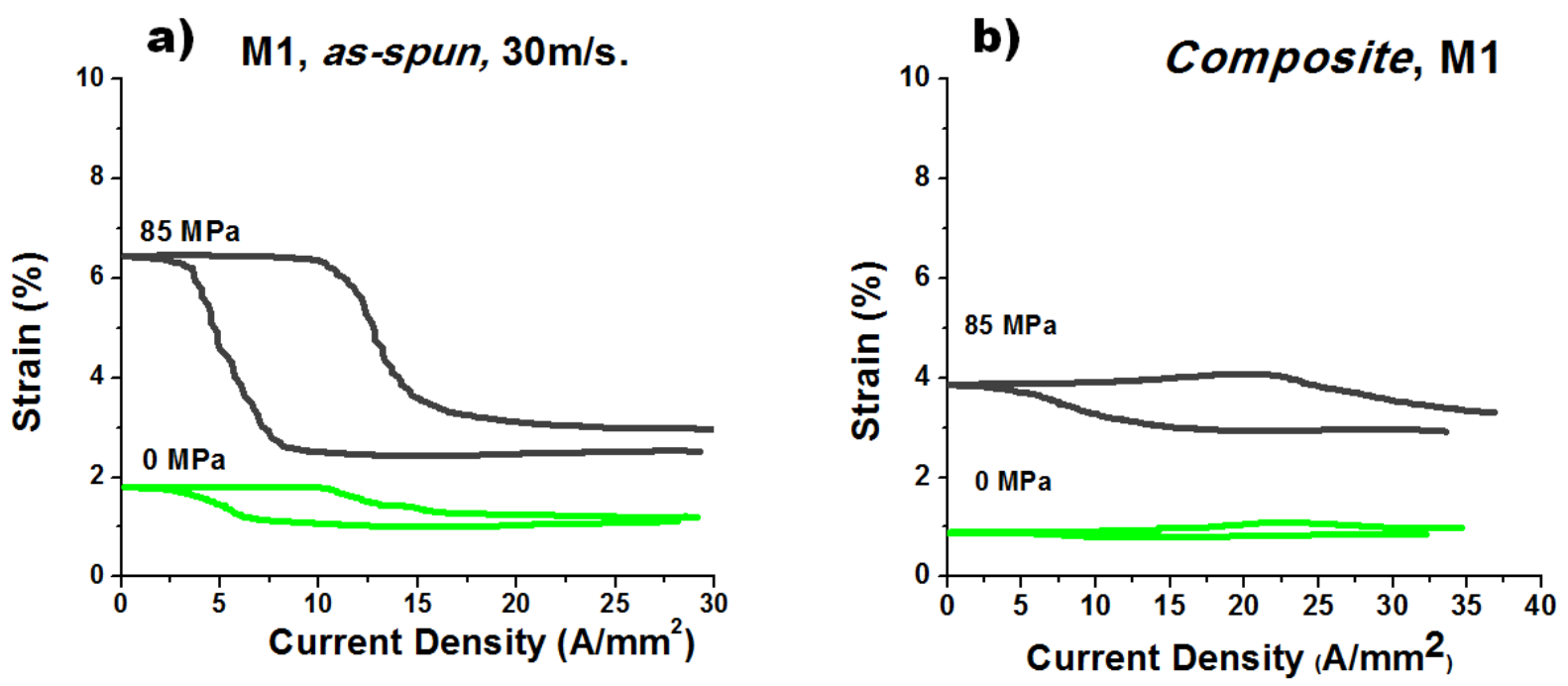

Figure 7. Curves of current density versus strain for the: (a) NiTi ribbon, (b) smart composite material.

Table 3. Current density $\left(\mathrm{A} / \mathrm{mm}^{2}\right)$ at the phase transformations of the NiTi ribbon and the composite material applying $0 \mathrm{MPa}$ and $85 \mathrm{MPa}$.

\begin{tabular}{ccccccccc}
\hline \multirow{2}{*}{$\begin{array}{c}\text { Stress } \\
(\mathbf{M P a})\end{array}$} & \multicolumn{3}{c}{ SMA Ribbon M1 30 m/s As-Spun } & \multicolumn{4}{c}{ Composite Material M1 } \\
\cline { 2 - 8 } & $\begin{array}{c}\mathrm{DC}_{\mathrm{As}} \\
\left(\mathrm{A} / \mathrm{mm}^{2}\right)\end{array}$ & $\begin{array}{c}\mathrm{DC}_{\mathrm{Af}} \\
\left(\mathrm{A} / \mathrm{mm}^{2}\right)\end{array}$ & $\begin{array}{c}\mathrm{DC}_{\mathrm{Ms}} \\
\left(\mathrm{A} / \mathrm{mm}^{2}\right)\end{array}$ & $\begin{array}{c}\mathrm{DC}_{\mathrm{Mf}} \\
\left(\mathrm{A} / \mathrm{mm}^{2}\right)\end{array}$ & $\begin{array}{c}\mathrm{DC}_{\mathrm{As}} \\
\left(\mathrm{A} / \mathrm{mm}^{2}\right)\end{array}$ & $\begin{array}{c}\mathrm{DC}_{\mathrm{Af}} \\
\left(\mathrm{A} / \mathrm{mm}^{2}\right)\end{array}$ & $\begin{array}{c}\mathrm{DC}_{\mathrm{Ms}} \\
\left(\mathrm{A} / \mathrm{mm}^{2}\right)\end{array}$ & $\begin{array}{c}\mathrm{DC}_{\mathrm{Mf}} \\
\left(\mathrm{A} / \mathrm{mm}^{2}\right)\end{array}$ \\
\hline 0 & 10.0 & 14.2 & 6.4 & 3.5 & 9.26 & 31.79 & 8.57 & 5.94 \\
85 & 11.1 & 14.7 & 7.5 & 3.9 & 21.44 & 35.7 & 14.9 & 3.32 \\
\hline
\end{tabular}

The thermomechanical study reported in this section let us observe the behavior of the developed composite material when it is activated by electrical current and temperature, via Joule effect, also considering the effect of stress. These results show that martensitic transformation is carried out in the NiTi ribbon inside the composite material. So, the SMA ribbon provides the composite material, for instance, with the ability to do work, to lift loads and to conduct electricity. The response of an external magnetic field is presented in the next section. 


\subsection{Magnetic Response of the Composite Material}

The displacement of the magnetic hybrid material and the composite material as a response of an applied external magnetic field is the focus of this section. Each sample is placed in a cantilever beam configuration as observed in Figure 8. An external magnetic field produced by applying an electrical current to an electromagnetic coil causes its bending (see Figure 9); when the magnetic field is turned off, the composite material returns to its original position. The movements of the samples are recorded with a Leica IC80 HD camera mounted on a Leica M80 stereomicroscope. The analysis of the images is done with the LAS Interactive Measurement software.

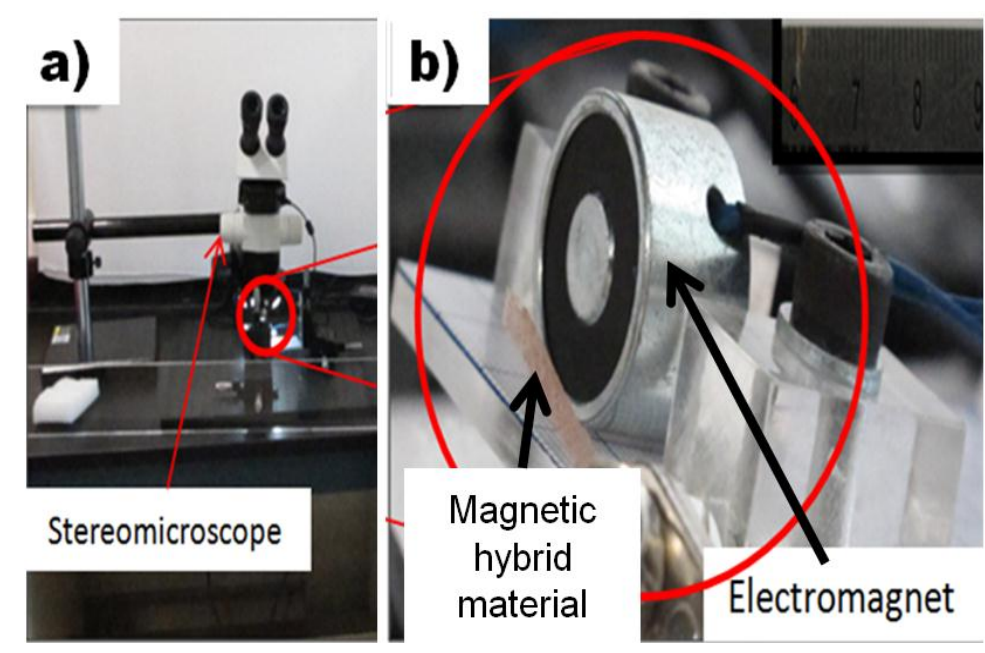

Figure 8. Experimental setup for the magnetic experimentations. (a) General view including the stereomicroscope Leica M80. (b) Zoom over the electromagnet and the magnetic hybrid material in a cantilever configuration.
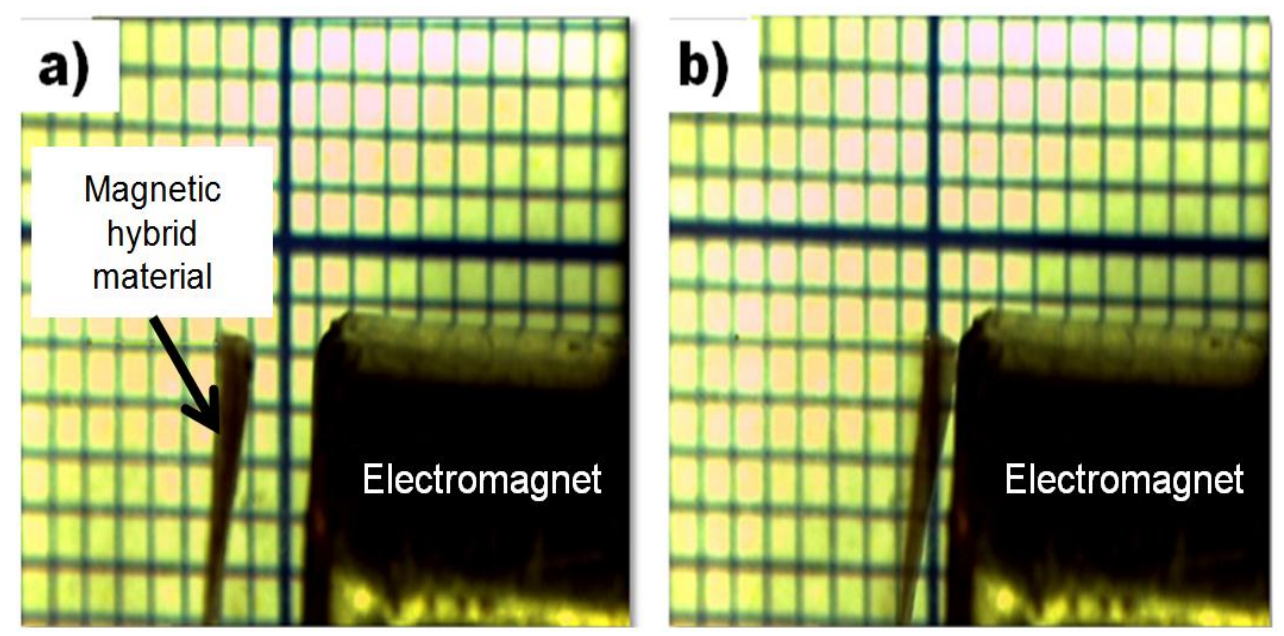

Figure 9. Displacement of the composite material when an external magnetic field is applied (top-view). (a) Initial position. (b) Final position.

The samples have been placed at different initial distances from the electromagnet. Figure 10a depicts the displacement curves of the magnetic hybrid samples, with different lengths, as a function of the initial distance between the sample and the electromagnet. The applied magnetic field is 500 Oe. 
This value has been measured with a Tesla/Gauss Meter KOSHAVA 5. As expected, if the sample is closer to the electromagnet or if it is longer, the displacement increases. The relationship between the physical properties and the displacement response is a topic of actual research. Table 4 summarizes the maximal displacement of each sample, according to its length. Figure 10b shows the displacement curves of the composite material versus the initial distance between the sample and the electromagnet for three applied magnetic fields: 500, 2000, and 5000 Oe. The length of the tested sample is $35 \mathrm{~mm}$. The response of the composite material is similar to that of the magnetic hybrid material. Additionally, by applying $5000 \mathrm{Oe}$, the maximal displacement is near $5 \mathrm{~mm}$, a good displacement for actuating applications, despite the high energy required. This composite should also be used in sensing applications. For example, it could be implemented as a sensor during magnetic flux leakage inspection for the oil and gas industry in order to detect corrosion zones in steel by distinguishing changes in the magnetic field between steel and steel oxides.
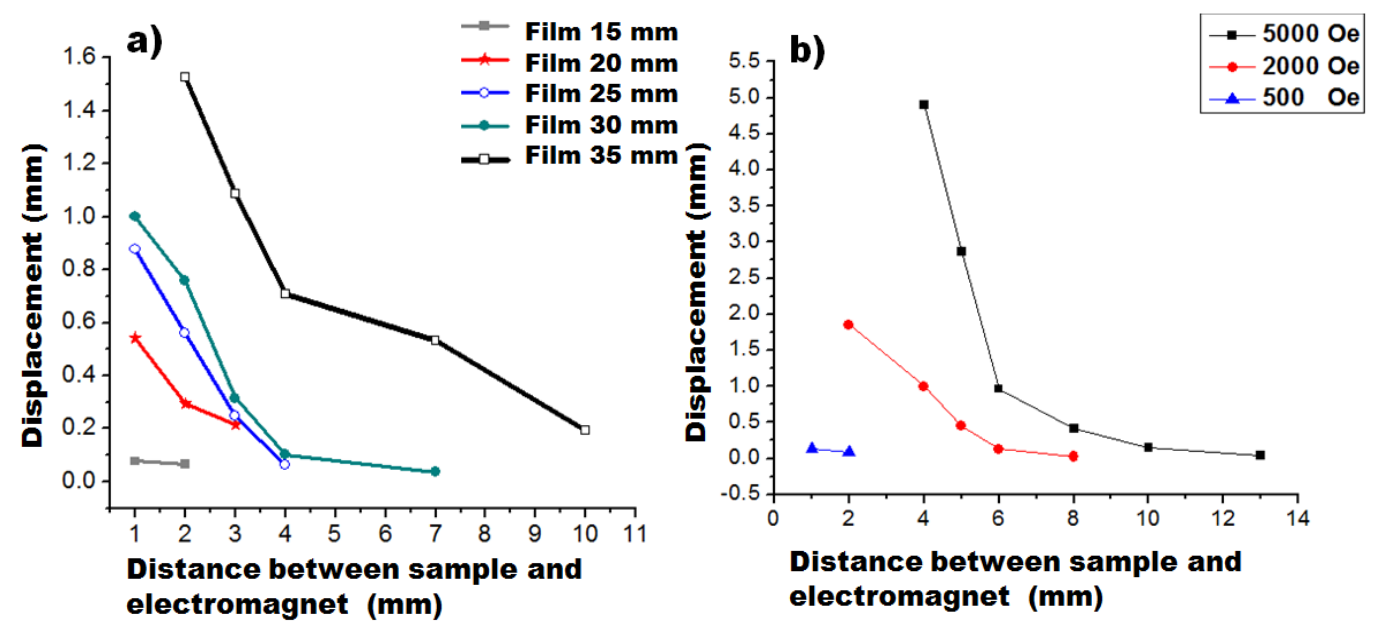

Figure 10. Maximal displacement curves of the samples versus the initial separating distance between these and the electromagnet for the: (a) magnetic hybrid film, (b) smart composite material.

Table 4. Maximal displacements for each evaluated length of the magnetic hybrid samples (external magnetic field: 500 Oe).

\begin{tabular}{lccccc}
\hline Hybrid film length $(\mathrm{mm})$ & 15 & 20 & 25 & 30 & 35 \\
\hline Maximal displacement $(\mathrm{mm})$ & 0.077 & 0.543 & 0.878 & 1.000 & 1.526 \\
\hline
\end{tabular}

In this section, the experimental response of the smart composite material has been evaluated. On the first hand, results confirm that this novel material can be activated by different stimuli: electrical current, temperature (via Joule effect), stress and magnetic field. On the other hand, the multiphysic transduction is also verified. Thus, the smart composite material combines the shape memory and the magnetic properties, in addition to the polymeric properties of the hybrid material.

\section{Conclusions}

A smart composite material with multiphysic transduction has been presented. It could be activated by the stimuli of electrical current, temperature, stress and magnetic field. The relation of mass is 
18.3\% NiTi ribbon and $81.7 \%$ magnetic hybrid film. DSC results show that transformation temperatures of the NiTi ribbon and the glass transition temperature of the magnetic hybrid material are nearby. This is very important for future possible applications because both effects can merge, obtaining only one macroscopic mechanical response on the smart composite material. The smart composite material presents a small delay of transformation during warming and cooling because the hybrid film acts like a thermal insulator. Thermomechanical results indicate that the hybrid material acts as a mechanical reinforcement, since it is observed that the SATWME of the smart composite is lower than the SATWME of the SMA ribbon. The density current values of the phase transformations during cooling and heating were clearly identified with the thermomechanical apparatus developed in our laboratory, even if during DSC tests this was not possible. Finally, the displacements obtained by applying external magnetic fields are interesting for actuating applications. Even the sample is separated from the electromagnet with a distance of some millimeters, the sensibility of the magnetic response is maintained. This is one of the most interesting advantages of magnetic actuators. In fact, this composite should be used in actuating applications where the magnetic field is the controlling signal or in sensing applications where the magnetic field must be measured.

Thus, obtained results demonstrate that the smart composite material can be activated by temperature, electrical current, stress and/or magnetic field, offering good expectations for actuating applications with multiphysic transduction. Further works will deal with the study of the mass relation between the SMA ribbon and the magnetic hybrid material, and the concentration of iron oxide nanoparticles in the hybrid material, in order to improve the mechanical and magnetic response of the composite material. Other magnetic tests will also be done to analyze the relationship between the physical properties and the magnetic behavior of the composite. Besides this, a dedicated application availing multiphysic transduction will be designed, simulated and fabricated.

\section{Acknowledgments}

This work is supported by the CONACYT (82515 and 155696 projects) and the CIAM (107462 projects).

\section{Author Contributions}

This work is based on the $\mathrm{PhD}$ thesis of Osvaldo Lomas-González. Beatriz López-Walle contributed to thermomechanical and magnetic experimentations. She wrote the final and revised versions of the paper. Enrique López-Cuellar is the thesis director of Lomas-Hernández and he contributed to the SEM and DSC characterizations and the revised versions. Edgar Reyes-Melo developed the synthesis processes of the magnetic hybrid materials based on CMC and PVB, the DSC analysis and the revised versions. Osvaldo Lomas-González wrote the first version of this article. Walman B. de Castro contributed to the fabrication of the SMA ribbons. All the authors approved all the content of the submitted manuscript.

\section{Conflicts of Interest}

The authors declare no conflict of interest. 


\section{References}

1. Zheng, Y.J.; Cui, L.S.; Schrooten, J. Basic design guidelines for SMA/epoxy smart composites. Mater. Sci. Eng. 2005, 390, 139-143.

2. Jani, J.M.; Leary, M.; Subic, A.; Gibson, M.A. A review of shape memory alloy research, applications and opportunities. Mater. Des. 2014, 56, 1078-1113.

3. De Araujo, C.J.; da Silva, N.J.; da Silva, M.M.; González, C.H. A comparative study of Ni-Ti and $\mathrm{Ni}-\mathrm{Ti}-\mathrm{Cu}$ shape memory alloy processed by plasma melting and injection molding. Mater. Des. 2011, 32, 4925-4930.

4. Xu, Y.; Otsuka, K.; Yoshida, H. A new method for fabricating SMA/CFRP smart hybrid composites. Intermetallics 2002, 10, 361-369.

5. Wei, Z.G.; Sandstrom, R.; Miyazaki, S. Shape memory materials and hybrid composites for smart systems. J. Mater. Sci. 1998, 33, 3763-3783.

6. Botshekanan, D.M.; Khalili, S. Frequency analysis of sandwich plate with active SMA hybrid composite face-sheets and temperature dependent flexible core. Compos. Struct. 2015, 123, 408-419.

7. Damanpack, A.; Aghdam, M.; Shakeri, M. Micro-mechanics of composite with SMA fibers embedded in metallic/polymeric matrix under off-axial loadings. Eur. J. Mech. A Solids 2015, 49, 467-480.

8. Huston, K. Polymer sensoried microgrippers using SMA actuation. In Proceedings of the IEEE ICRA, Roma, Italy, 10-14 April 2007; pp. 820-825.

9. Lim, T.M.; Zhang, D. Design and parameter estimation of hybrid magnetic bearings for blood pump applications. Mech. Syst. Signal Process. 2009, 23, 2352-2382.

10. Yu, Y.; Dun, Y. Analysis of hybrid magnetic bearing with a permanent magnet in the rotor by FEM. IEEE Trans. Magn. 2006, 42, 1363-1366.

11. Guo, S.; Shi, L.; Asaka, K. IPMC actuator-based an underwater microrobot with 8 legs. In Proceedings of the IEEE ICMA, Takamatsu, Japan, 5-8 August 2008; pp. 551-556.

12. Sanusi, K.; Ayodele, O.; Khan, M. A concise review of the applications of NiTi shape-memory alloys in composite materials. South Afr. J. Sci. 2014, 110, 22-26.

13. López-Walle, B.; Romo-Rico, J.; Puente-Córdova, J.; Reyes-Melo, M. Synthesis and mechanical characterization of magnetic hybrid materials with PVB as polymeric matrix for micro-actuation applications. MRS Proc. 2014, 1708, doi:10.1557/opl.2014.525.

14. Lomas-González, O.; López-Cuellar, E.; López-Walle, B.; José de Araujo, C.; Reyes-Melo E.; Gonzalez, C.H. Thermomechanical behavior of a composite base on a NiTi ribbon with a magnetic hybrid polymer. Mater. Today Proc. 2015, 2, S785-S788.

15. Nuñez-Mendoza, E.; López Cuellar, E.; de Castro, W.B.; López Walle, B. Effect of the linear velocity during the melt spinning process on shape memory transformation of Ni-Ti ribbons. MRS Proc. 2012, 1373, 119-124.

16. López-Walle, B.; Reyes-Melo, E. Characterization and dynamics of polymer microactuators. In Smart Materials-Based Actuators at the Micro/Nano-Scale: Characterization, Control and Applications; Rakotondrabe, M., Ed.; Springer: New York, NY, USA, 2013; pp. 57-82. 
17. López Walle, B.; López Cuellar, E.; Colás Márquez, R.; Lomas-González, O.; de Castro, W.B. Automatic electromechanical characterization of $\mathrm{Ti}-\mathrm{Ni}$ shape memory alloys ribbons. In Proceedings of the MRS International Materials Research Congress (IMRC), Cancun, Mexico, 11-15 August 2013.

18. Kirchberg, S.; Rudolph, M.; Ziegmann, G. Nanocomposites based on technical polymers and sterically functionalized soft magnetic magnetite nanoparticles. Synthesis, processing, and characterization. J. Nanomater. 2012, 2012, 1-8.

19. Olbricht, J.; Yawny, A.; Pelegrina, J.L. On the stress-induced formation of R-phase in ultra-fine-grained Ni-rich NiTi shape memory alloys. Metall. Mater. Trans. A 2011, 42, 2556-2574.

20. Nam, T.H.; Noh, J.P.; Jung, D.W.; Kim, Y.W.; Im, H.J.; Ahn, J.S.; Mitani, T. The R phase transformation in Ti-49 $\mathrm{Ni}$ (at.\%) shape memory alloy ribbons fabricated by melt spinning. $J$. Mater. Sci. Lett. 2002, 21, 11-13.

21. Frenzel, J.; George, E.P.; Dlouhy, A.; Somsen, C.; Wagner, M.X.; Eggeler, G. Influence of Ni on martensitic phase transformations in NiTi shape memory alloys. Acta Mater. 2010, 58, 3444-3458.

22. Zarnetta, R.; Takahashi, R.; Young, M.L.; Savan, A.; Furuya, Y.; Thienhaus, S.; Maaß, B.; Rahim, M.; Frenzel, J.; Brunken, H.; et al. Identification of quaternary shape memory alloys with near-zero thermal hysteresis and unprecedented functional stability. Adv. Funct. Mater. 2010, 20, 1917-1923.

23. Yan, X.; van Humbeeck, J. Effect of annealing on martensite stabilization due to deformation via cooling under stress in cold-worked NiTi thin wire. Mater. Sci. Eng. A 2012, 558, 737-741.

24. He, X.M.; Rong, L.J.; Yan, D.S.; Li, Y.Y. TiNiNb wide hysteresis shape memory alloy with low niobium content. Mater. Sci. Eng. A 2004, 371, 193-197.

(C) 2015 by the authors; licensee MDPI, Basel, Switzerland. This article is an open access article distributed under the terms and conditions of the Creative Commons Attribution license (http://creativecommons.org/licenses/by/4.0/). 